\title{
Lina Bo Bardi: tempo, história e restauro
}

Ana Carolina de Souza Bierrenbach*

\section{Resumo}

Este artigo pretende examinar a conexão entre a teoria e a prática da restauração arquitetônica na obra de Lina Bo Bardi. A arquiteta considera que essa relação é fundamental. Este trabalho expõe vários conceitos elaborados por ela, ligados principalmente às concepções de tempo e história. Tais formulações estabelecem as bases para a teoria e, também, para a prática da restauração arquitetônica desenvolvidas por Lina Bo Bardi. Considera-se que a sua experiência restaurativa é extremamente coerente, e deve ser examinada com atenção por todos aqueles que se disponham a trabalhar com esse assunto.

Palavras-chave: História e teoria da restauração. Lina Bo Bardi.

\section{Lina Bo Bardi: time, history and restoration}

\begin{abstract}
This article aims to examine the connection between the theory and the practice of Lina Bo Bardi's work on architectural restoration; this relationship is considered fundamental to the architect herself. This article depicts many concepts of the architect's notions of history and time, which are the base on which her practical and theoretical work were established. Lina Bo Bardi's work is considered to be extremely relevant and one of the reasons for this is the coherence between her theoretical postulates and practice.
\end{abstract}

Keywords: History and theory of restoration. Lina Bo Bardi.

\section{Historicismo, espírito da época e progresso}

Durante os seus primeiros anos de permanência no Brasil (1), Lina Bo Bardi ainda mantém consigo muitas referências da Itália. O ambiente de formação da arquiteta, 
marcado por sua passagem pela Universidade de Roma, e posterior transferência para Milão, possibilita a ela um grande envolvimento com a arquitetura. Em poucos anos Lina Bo Bardi tem contato com os aspectos mais tradicionais e mais inovadores da disciplina arquitetônica. Passa dos ensinamentos de Gustavo Giovanonni a ter uma admiração por Giuseppe Terragni e a ser influenciada por Ernesto Rogers. E depois, Brasil, vasto campo de descobertas...

Da etapa em Roma, permanece um certo gosto amargo, cuja lembrança é suscitada em plena São Paulo dos anos de 1950. Em uma visita à Catedral da Sé, a análise do clima local denuncia o repúdio de Lina Bo Bardi à indiscriminada cópia de formas tradicionais, recurso amplamente difundido na sua época de estudante na Universidade de Roma:

Tal atmosfera veio ao nosso encontro brutalmente, com o odor de Roma, de louro queimado, com o som de músicas militares ao longo do Tibre. Reconhecemos [...] a remastigação estilística que nos envenenara na universidade e que nos impelira a abandoná-la. Seria possível que tais coisas tivessem chegado aqui? [...] Toda aquela arquitetura equivocada, inútil, vazia como uma pele soprada com a cúpula ridícula sobreposta, uma arquitetura que nem se quer (sic) se despetala em garbo culturalístico, uma arquitetura capaz de fazer-nos duvidar de uma religião que aceita um tal monumento. (BARDI, 1954, não pag.)

Tal crítica é tão veemente que chega a abalar até mesmo as crenças metafísicas da arquiteta. Há justificativas para essa postura de radical desprezo pela cópia dos estilos passados, com seus "babados e de suas franjas". Uma delas é a idéia do espírito da época. Esse conceito demonstra que a influência do Movimento Moderno (2) na sua formação se faz presente.

O Zeitgeist (espírito da época) (3) considera que as formas do passado estão se tornando obsoletas continuamente, sendo substituídas por outras, correspondentes às novas épocas históricas. Cada um dos períodos históricos possui alguma singularidade que o caracteriza, que marca sua diferença com relação às etapas anteriores e posteriores.

Quando Lina Bo Bardi aporta no Brasil, ela traz consigo essa idéia de que a arquitetura é a expressão singular da vida dos homens de seu tempo, a sua 
projeção no mundo. Desse modo, utilizar-se das aparências de épocas superadas é para a arquiteta algo incoerente: "Somos modernos. As casas que construímos são bem de hoje. [...] Benvindas sejam as novas construções de materiais modernos, expressão (sic) da consciência coletiva e do respeito à humanidade." (BARDI, 1958, não pag.)

Essa citação exprime dois pontos fundamentais para a caracterização das especificidades de uma nova época histórica que se vislumbra. Trata-se do tempo da solidariedade humana, da responsabilidade social. Esse novo tempo deve ultrapassar as "acrobacias formalísticas" e os conteúdos abstratos. Mas não deixa de ter as suas próprias características formais. Essas estão relacionadas com as possibilidades plásticas do concreto armado, que conduzem a uma forma "livre, desabrochada, perfeita da perfeição da máquina." (BARDI, 1951, p. 6-8)

Nota-se que nos primeiros anos em terras brasileiras, a arquiteta ainda se encontra absorvida pelas possibilidades desta nova arquitetura que denomina postracionalista. E por vezes expressa sua adesão de modo contundente, reafirmando a existência de certas posturas básicas que devem ser adotadas, em coerência com o momento histórico. Observe-se este trecho no qual Lina Bo Bardi faz uma crítica a um jardim na Bahia:

O torto é por sua natureza o êrro, o incômodo, o irracional. [...] O mais curto caminho é a linha reta. Ora, nêsse jardim da Bahia, o torto e o direito contribuíram para o confusionismo (sic), isto é, inquietude, irracionalidade. [...] O caminho mais racional é o reto. (BARDI, 1952, p. 16).

O caminho reto também serve para designar uma metáfora para o progresso. Em contraposição a um movimento cíclico de eternas repetições, acredita-se em um movimento portador de mudanças contínuas, de desenvolvimentos, até uma culminação.

Nos seus primeiros anos no Brasil, Lina Bo Bardi está impregnada pelos pensamentos positivos do Movimento Moderno. Sua crença nas potencialidades do progresso ainda se encontra inabalada: 
É claro que temos muito respeito aos objetos antigos, os verdadeiros, e que conservamos também dentro de casa, mas como relíquias, que de vez em quando trancamos no armário. Mas violentar uma época impondo-lhe embalsamentos de gesso e papelão, significa desconhecer o progresso fatigante e doloroso da humanidade, que a incompetência, o diletantismo e a ignorância fazem recuar de quilômetros a cada centímetro que ela (sic) consegue conquistar em seu caminho para frente. (BARDI, apud FERRAZ, 1993, p. 11).

A partir da década de 1970 Lina Bo Bardi já é capaz de denunciar os danos provocados por essa noção de um ideal potencial. Comentários sobre a falência da utopia modernista mostram a sua descrença:

A tomada de consciência coletiva de mais de um quarto da população mundial, aquela que acreditou no progresso ilimitado, já começou. [...] A regeneração através da arte, credo da Bauhaus, revelou-se mera utopia, equivoco cultural ou tranqüilizante das consciências. (BARDI, 1994, p. 13)

A arquiteta vai percebendo que o tal tempo novo antes vislumbrado não tem efetivação no Ocidente. E o Brasil oferece a Lina Bo Bardi a amarga experiência de vivenciar esses descaminhos do progresso. Ela se depara uma vez mais com o autoritarismo (4). Todas as potencialidades nacionais são asfixiadas, assim como a vigorosa esperança bobardiana. Ao longo dos anos a arquiteta aprende a driblar esse sentimento, mas sua fé no progresso da humanidade já se encontra irremediavelmente abalada.

Somente onde o progresso é tratado conjuntamente com a civilização, há alternativas para a consolidação das utopias. É por esse aspecto civilizatório, que conjuga o respeito à natureza e ao homem, que Lina Bo Bardi considera o Japão como um marco a ser valorizado:

O que os homens conquistaram no decorrer dos tempos foi o progresso, a civilização sobreviveu ameaçada. A civilização é a Realidade Natural sempre presente, a atenção, o respeito aos mínimos detalhes naturais - e nesse sentido é primordial - do homem. [...] $\mathrm{O}$ que o Ocidente tem feito, até hoje, é rigorosamente separar o Progresso da Civilização, o que não acontece no Oriente. O Japão guarda ferozmente a sua civilização profundamente ligada à observação respeitosa da Natureza paralelamente ao 'progresso'. [...] Quem atravessa as Américas rumo ao Extremo Oriente sente nos grandes horizontes, na calma da Natureza, [...] que a opção do Progresso no Ocidente não é necessariamente a única, 
outras opções poderiam ter sido feitas com os mesmos resultados. A opção escolhida pelo Ocidente deu resultados potentes, mas o custo é enorme. (BARDI, apud FERRAZ, 1993, p. 209)

A intransigência ao pastiche e o apelo ao Zeitgeist dizem respeito à formulação do entendimento bobardiano da história. Essa não pode ser entendida como cíclica, repetitiva, pertencente a uma estabilidade eterna. Ao sublinhar que as épocas passadas estão superadas, a arquiteta pretende evitar repetições enganosas, e promover o direito que o presente tem à sua própria manifestação.

Não se deve tomar estágios anteriores como modelos, efetuar um transporte de formas e estilos dos seus momentos originais para etapas posteriores. As formas são específicas de cada momento histórico. Isso a leva à compreensão de que é possível estabelecer qual é a "verdadeira expressão formal" de cada época.

Todas essas considerações contidas nesses discursos de Lina Bo Bardi fazem parte dos preceitos do Movimento Moderno. Mas há que se considerar que a arquiteta, além de estar sendo influenciada pelos arquitetos modernos, já se encontra envolvida nos debates que formulam a sua reavaliação (5). E, mais ainda, já está abrindo caminho para a sua descoberta do Brasil.

E é por se encontrar na encruzilhada de todos esses caminhos, que o seu entendimento da história não se afina plenamente com aquele difundido pelo Movimento Moderno. Se o futuro ainda pode ser considerado o reservatório das esperanças, o passado se apresenta de maneira peculiar. Não é ruptura ou repetição, mas sim construção.

\section{Tempo histórico}

A percepção do tempo para os integrantes do Movimento Moderno pode ser vista a partir da metáfora da linha reta. Os homens vão avançando por esse caminho, deixando para trás etapas já concluídas. É um percurso que considera o presente como unidade, portador de uma expressão que Ihe é própria. Também é um caminho que aponta para frente, em direção a um ponto culminante. Tempo progressivo. 
No momento em que Lina Bo Bardi se estabelece no Brasil, ela ainda está seduzida por essa imagem do caminho para frente, do progresso. Ela aponta como positivos esses valores revolucionários difundidos pelo Movimento Moderno. O que mais a encanta é justamente o aspecto das mudanças que se vislumbram: a possibilidade de um novo tempo, onde as grandes esperanças da humanidade se efetivem.

Mas a arquiteta que acredita nas possibilidades do futuro é a mesma que não descarta a importância do passado. Nesse sentido, a apreensão temporal de Lina Bo Bardi afasta-se daquela difundida pelo discurso do Movimento Moderno. Para ela, é impossível uma compreensão do tempo que desconsidere as etapas já percorridas.

Lina Bo Bardi insiste em um ponto: entre o moderno e a história não há cisão. Ao contrário dos preceitos difundidos pelo Movimento Moderno que apontam para a ruptura entre os tempos históricos, a arquiteta é contundente ao afirmar que é preciso estabelecer contato entre a vida passada e a presente: "Não existe fratura entre o assim chamado 'moderno' e a história, visto ser o 'moderno' antes o produto da história mesma, através do qual é possível evitar as repetições de experiências superadas." (BARDI, 1957, p. 6)

Essa compreensão do tempo histórico em Lina Bo Bardi (6) está profundamente ligada à reavaliação do Movimento Moderno empreendida na Itália entre as décadas de 1940 e 1950. De fato, é possível compreender melhor as posturas da arquiteta quando se leva em consideração o debate italiano realizado em torno do Movimenti di Studi per l'Architettura (MSA), fundado em Milão no ano de 1946. Entre as figuras mais influentes nesse panorama está Ernesto Nathan Rogers (7).

Um das questões fundamentais levantadas por Rogers diz respeito à necessária integração entre o presente e o patrimônio herdado pela experiência. $\mathrm{O}$ arquiteto sugere que até mesmo o Movimento Moderno tem que ser posicionado dentro da trajetória completa da história da arquitetura. Rogers afirma a importância do sentido da continuidade histórica. Lina Bo Bardi também afirma a importância da 
continuidade histórica. Para a arquiteta, tal termo está vinculado à aquisição de uma consciência histórica:

O país se industrializou, bem ou mal. O passado não volta. Importantes são a continuidade e o perfeito conhecimento de sua história. A defesa do patrimônio cultural não pode ter fraturas. As fraturas culturais, a indiferença e o esquecimento são próprios das classes médias e altas - o povo não esquece - é o único capaz de constituir-se numa continuidade histórica sem fraturas. (BARDI, 1994, p. 76)

Mas durante os anos de 1950, a noção de continuidade encontra também outras implicações. Tal como Rogers, Lina Bo Bardi considera que o presente deve ser compreendido dentro da ordem da história, já que ele é o seu produto. O passado traz uma lição histórica, oferece os meios para a compreensão do presente. $O$ presente, por sua vez, também deve ir de encontro ao passado, estabelecendo com ele uma ligação fecunda. O passado é capaz de iluminar o presente, de fornecer sua compreensão. O presente, por sua vez, é capaz de iluminar o passado: "Para se eliminar a cisão entre o presente e o passado, necessária se torna a consideração histórica do resultado arquitetônico ao qual chegamos hoje. Desenvolvimento histórico não significa conciliação, e sim exame crítico profundo." (BARDI, 1957, p. 69)

Dentro da sua reavaliação dos postulados do Movimento Moderno, Lina Bo Bardi consegue conjugar dois aspectos antes tidos como antagônicos: o passado e o presente. As etapas históricas anteriores não podem ser simplesmente ignoradas. Entretanto, a arquiteta ainda opera dentro das mesmas bases modernistas, considerando o tempo a partir de uma percepção linear e progressiva.

Mas o pensamento da arquiteta revela surpresas. Ao mesmo tempo em que se encontram nos seus discursos traços da herança do Movimento Moderno, Lina Bo Bardi já consegue formular outro possível entendimento do tempo, que rompe totalmente com o esquema linear e progressivo difundido pelos seus integrantes. É isso o que se evidencia em alguns dos seus textos sobre museus, elaborados nos anos 40, e que sugerem, inclusive, uma noção de continuidade diferenciada daquela apresentada anteriormente:

Um recanto de memória? Um túmulo para múmias ilustres? Um depósito ou um arquivo de obras humanas que, feitas pelos homens para os homens, já são obsoletas e devem ser 
administradas com um sentido de piedade? Nada disso. Os museus novos devem abrir suas portas, deixar entrar o ar puro, a luz nova. Entre o passado e o presente não há solução de continuidade. (BARDI, apud FERRAZ, 1993, p. 44)

Mais uma vez ela coloca a necessidade de se efetivar um entrosamento entre a vida passada e a presente. Mas sugere que essa ligação não se paute por uma solução de continuidade:

O fim do Museu é o de formar uma atmosfera, uma conduta apta a criar no visitante a forma mental adaptada à compreensão da obra de arte, e nesse sentido não se faz distinção entre obra antiga e moderna. No mesmo objetivo a obra de arte não é localizada segundo um critério cronológico mas apresentada quase propositalmente no sentido de produzir um choque que desperte reações de curiosidade e de investigação. [...] Desta maneira as obras de arte antiga acabaram por se localizar numa nova vida, ao lado das modernas, no sentido de virem a fazer parte da vida de hoje, no quanto possível. (BARDI, apud FERRAZ, 1993, p. 46)

É com essas observações sobre os museus - e com sua atuação prática neles que Lina Bo Bardi passa a substituir a imagem do tempo como um leito de um rio, por aquela de um turbilhão. As obras de arte, ou os acontecimentos do passado e do presente são extraídos de seu posicionamento estático, ancorado em uma fictícia linha temporal, para integrarem uma nova e dinâmica relação: "O tempo linear é uma invenção do ocidente, o tempo não é linear, é um maravilhoso emaranhado onde, a qualquer instante, podem ser escolhidos pontos e inventadas soluções, sem começo nem fim." (BARDI, apud Ferraz, 1993, p. 327)

Nessa percepção temporal, cabe ao presente da consciência humana iluminar o passado. É o pensamento que deve envolver-se no emaranhado e extrair dele novas ligações que independam de seqüências cronológicas. É ele quem estabelece uma temporalidade descontínua.

É esta a grande conquista de Lina Bo Bardi: ela consegue romper definitivamente com aquela compreensão temporal que mantém os acontecimentos rigidamente encadeados em uma linha do tempo abstrata. No seu lugar é reposto um maravilhoso emaranhado, e é nele que a arquiteta recolhe os acontecimentos e os vincula de um modo inusitado e provocativo. Sem começo e nem fim. 


\subsection{Origem}

Se não há uma linha do tempo, se não há começo nem fim, não existe nenhum acontecimento que possa ser reclamado como inaugural ou conclusivo. Desse modo, não se almeja o retorno a um início imaculado, à gênese dos acontecimentos. Tampouco se deseja um lançamento em um futuro utópico, atingido passo a passo através de uma linha de desenvolvimento.

Não se pretende considerar algum ponto do passado como o gerador permanente dos fatos posteriores. A referência às origens não visa encontrar referências fixas, que se mantenham sempre válidas. Busca um reencontro com o passado que se renove a cada momento, que toque o presente a cada instante, e que o transforme.

A validade da história da arquitetura depende da manutenção dessa tensão entre os tempos históricos. Lina Bo Bardi afirma esse caráter mutante da relação com o passado: "O coliseu, por exemplo, ainda é uma arquitetura porque o homem ainda pode possuí-lo numa interpretação que, hoje, tem um caráter diverso das origens." (BARDI 1957, p. 43).

A arquiteta procede a sua própria imersão nas origens da arquitetura brasileira. Ela é capaz de cavocá-la a fundo, e dela extrair os elementos menos aparentes, aqueles que são abafados pela historiografia oficial. Sua busca tira esses pontos significativos do emaranhado, e os expõe à luz. As raízes brasileiras comportam aspectos indígenas, africanos e europeus; agregam referências eruditas e populares.

Com essa ampla visão das raízes da arquitetura nacional, Lina Bo Bardi contrapõese ao órgão nacional de preservação - o Sphan (7), que cria uma genealogia para a arquitetura brasileira a partir das construções coloniais e barrocas:

A arquitetura contemporânea brasileira não provém dos jesuítas, mas do pau-a-pique, do homem solitário. [...] Provém da casa do seringueiro. [...] Possue em sua resolução furiosa de fazer, uma sabedoria e uma poesia do homem do sertão que não conhece as grandes cidades da civilização e os museus. [...] Essa falta de polidez, esta rudeza, êste tomar e 
transformar sem preocupações (sic), é a força da arquitetura contemporânea brasileira. (BARDI, apud FERRAZ, 1993, p. 66).

Desse mergulho nas origens não se extraem normas que direcionem a arquitetura contemporânea. O olhar que se dirige às raízes não busca a conservação de formas e materiais. Procura avaliar as possibilidades criativas originais e trazê-las ao encontro das instâncias presentes, sem com isso pretender repeti-las. Não se cogita a possibilidade de algum retorno no tempo.

A referência à origem não pode significar a eterna repetição de modelos anteriores e a morte dos acontecimentos posteriores, mas sim a vida, na sua plenitude. A relação entre os tempos históricos tem que ser mútua e construtiva. Transformar todas as partes envolvidas.

\subsection{Saltos}

Lina Bo Bardi se desloca pelo emaranhado temporal através de saltos, promovendo ligações inusitadas entre os acontecimentos históricos. O salto extrai os fatos da linha unidirecional e abstrata, e os integra em uma outra temporalidade, qualificada.

A arquiteta vai gradativamente aprendendo a se deslocar por essa outra temporalidade, encontrando os aspectos negligenciados pela história brasileira. Ela a cavoca a fundo, explora seus aspectos mais ocultos, mas nem por isso menos significativos:

A história brasileira não está bem contada, e há coisas importantes como os quilombos, a violência... É uma história bonita, junto com coisas terríveis. O povo brasileiro tem uma imagem que o faz muito gracioso. Mas a história do Brasil é outra, é um dos povos mais violentos do mundo, no sentido poético. (BARDI, 1985, p. 31)

E os saltos que Lina Bo Bardi dá por esse ardente emaranhado, vão revelando as sutilezas de sua história. O seu olhar pousa na cultura material do homem: revela a riqueza da produção de objetos populares, que partem de fontes miseráveis para chegarem a resultados surpreendentes; desloca-se para a arquitetura e extrai dela elementos abafados pela historiografia unilinear. 
Nos anos de 1950 a arquiteta já se encontra empenhada em praticar esses saltos qualitativos. Observe-se o texto no qual é relatada uma visita à Catedral de São Paulo. Nele Lina Bo Bardi resgata a "outra" arquitetura religiosa brasileira. Ela a vislumbra silenciada nos mais diversos recantos do país, e a promove:

Ao olharmos fugazmente aos anjos de bronze dourado, o mosaico de ouro e o mármore côr de rosa, pensamos nas "outras catedrais", em tôdas (sic) as catedrais enxaguadas de cal ou deixadas apenas com tijolos, pobres e miseráveis entre dois coqueiros ou rente ao litoral, catedrais de uma aldeia de pescadores ou lavradores velando um cemitério cheio de plantas selvagens, onde a obra de arte se revela de improviso, não com abundâncias decorativas, mas através de uma linguagem diretamente. (BARDI, 1954, não pag.).

É importante sublinhar que nos anos de 1950 a arquiteta ainda mantém um discurso pautado pela linearidade da história. Mas suas palavras já revelam a vigência de uma outra percepção temporal: aquela que capta os eventos na sua descontinuidade e que se movimenta ativamente pelo emaranhado histórico. É esse o entendimento que vai prevalecer.

\section{Presente histórico}

É surpreendente como a concepção temporal de Lina Bo Bardi vai se modificando durante a sua vida. Ela abandona por completo o entendimento do tempo exterior ao pensamento, que fixa os eventos em uma linha reta e abstrata, e o substitui por um tempo interior à consciência, que encaixa os acontecimentos em novas e dinâmicas relações.

A leitura do passado passa a se ancorar no presente da consciência humana. É a atualidade do pensamento que lança seu olhar para a história, capta todas as imagens que Ihe são significativas, extraindo os acontecimentos do esquecimento.

Cada vez que o presente recolhe esses pontos isolados no firmamento histórico e os reúne com um traço comum, forma-se uma constelação. Isso significa que cada presente tem a potencialidade de dar à história uma nova interpretação.

Lina Bo Bardi apresenta o conceito de Presente Histórico. A arquiteta contrapõe-se a um certo modo de apreensão do passado, que o considera alheio ao pensamento, 
encerrado em uma imagem eterna. Em oposição a esse entendimento, Lina Bo Bardi propõe que se efetue um outro tipo de encontro com o passado, que acompanhe a vida de todos os dias, que diga respeito ao presente diretamente. Eis a definição de presente histórico:

É preciso se liberar das "amarras", não jogar fora simplesmente o passado e toda a sua história; o que é preciso é considerar o passado como presente histórico. O passado, visto como presente histórico, é ainda vivo, é um presente que ajuda a evitar as arapucas... Frente ao presente histórico, nossa tarefa é forjar outro presente, "verdadeiro", e para isso não é necessário um conhecimento profundo de especialista, mas uma capacidade de entender historicamente o passado, saber distinguir o que irá servir para novas situações de hoje que se apresentam a vocês e tudo isso não se aprende somente nos livros. [...] Na prática, não existe o passado, o que existe é o presente histórico. (BARDI, 1992, p. 61-62).

O presente histórico exclui a possibilidade de que exista uma única e definitiva interpretação dos fatos passados e presentes. Ao se vislumbrar a história a partir do presente histórico, cada consciência humana é capaz de explorar o passado e o presente, e a partir deles formular a sua própria versão dos fatos. Isso significa que a história se encontra aberta a cada ser humano. Os homens se tornam plenamente ativos na construção da sua própria história. Hoje e amanhã. Tanto na escrita quanto na prática. A arquiteta explicita o conceito: "É calcular o Passado como Presente no sentido gramatical. Cabral está descobrindo o Brasil: é o presente histórico. Possibilitando que se reviva o Passado como Presente, pode-se descobrir novas coisas, não como lembranças." (BARDI, apud LEFÉVRE, 1991, p. 64)

Lina Bo Bardi, tal como os anjos do filósofo alemão Walter Benjamin (8), encontra uma abertura para que se rompa com a cronologia linear e abstrata. O presente histórico oferece a possibilidade para que a qualquer momento se interrompa o escoamento moroso da história e se estabeleçam presentes mais plenos, carregados de invenção e subversão.

É importante observar que esse conceito de presente histórico é fruto de uma maturação do pensamento bobardiano. Desde os seus discursos dos anos de 1950, a arquiteta considera que não há uma ruptura entre os tempos históricos, mas sim uma iluminação mútua. Lina Bo Bardi já não aceita uma compreensão do passado que chegue ao presente pré-determinada e concluída. O passado tem que ser 
querido e reanimado pelo presente. Esse, por sua vez, tem que ser tocado pelo passado, mas sem que isso acarrete em uma renúncia à contemporaneidade. É esse jogo produtivo entre os momentos históricos que possibilita à arquiteta manifestar sua conceituação de história, que é entendida do seguinte modo:

Como coisa viva e atual, revivida em seus problemas fundamentais dotados de transmissibilidade e fecundos de ensinamentos, essa história que, como é óbvio, não é aquela dos manuais escolares, monótona e de segunda mão, capaz apenas de sugerir a idéia de que o "passado" passou e não tem mais validade, e que o mundo começou hoje, atribuindo-se ao homem, assim, a tarefa de realizar sòzinho (sic) a experiência do "paraíso perdido"; mas, sim a história que não seja a mera "História" abstrata e sim a vida concreta e fecunda. (BARDI, 1957, p. 6).

A arquiteta vai abrindo caminho para o seu conceito de presente histórico. 0 passado vai deixando de ser algo exterior à consciência, para se fixar cada vez mais no presente do pensamento. Esse movimento torna-se mais nítido nos anos de 1970, quando Lina Bo Bardi deixa de lado sua afirmação de que a história seja capaz de transmitir fecundos ensinamentos. A partir desse momento a história não é mais mestra. Sua função é ativar um olhar presente para o passado que seja ao mesmo tempo vigilante e crítico.

É nesse momento que o presente histórico se instala com todo vigor. Com ele já não há mais possibilidade que os homens permaneçam estáticos diante do passado, do presente e do futuro. O presente histórico permite que a intervenção dos homens se efetive: possibilita a ruptura com o "escoamento moroso da infelicidade cotidiana e a instauração de um perigoso transtorno de felicidade". (GAGNEBIN, 1997, p. 130)

\section{Ruínas, monumentos e documentos}

Ruínas e antiguidades podem ter mais de um sentido, dependendo do modo como são apropriadas. Lina Bo Bardi nasce em um país no qual tais elementos proliferam. A avaliação que faz delas em certas circunstâncias é profundamente negativa. Ruínas e antiguidades podem ser a marca registrada de tragédias e de morte. Pompéia é uma cidade soterrada por ruínas. Veneza é uma cidade estagnada com suas antiguidades. Não interessam a Lina. 
Ruínas, portadoras do horror, têm que ser demolidas. As antiguidades, mumificadas e cheias de mofo têm que ser esquecidas. A única chance de sobrevivência para ruínas e antiguidades é a vida. Elas têm que ser queridas e reapropriadas.

As ruínas, tais como as antiguidades, representam os legados do passado, restos de um mundo que já não é mais. Elas atravessam o tempo, sofrendo modificações, até atingir o presente. Para Lina Bo Bardi, considerá-las somente como testemunhos desse tempo que já não é mais, é deixá-las padecer de insignificância. As ruínas têm que ser extraídas da sua decadência e reinstaladas na atualidade.

Para Lina Bo Bardi o que mais importa é essa relação construtiva que o presente deve estabelecer com o passado. Considera que é importante extrair dos registros históricos o outro que Ihes está implícito, o não sido. Lina Bo Bardi vê nas ruínas as potencialidades não realizadas da história, as promessas de felicidade não cumpridas, mas eventualmente realizáveis.

Além das ruínas, há ainda outros elementos que indiciam o passado, os quais fazem parte dos discursos de Lina Bo Bardi: os documentos e os monumentos.

Os documentos, assim como as ruínas, não testemunham o passado de uma forma a priore. Os documentos, esses restos fragmentários do passado, só ganham esse título quando alguém os atribui um valor histórico. Para Lina Bo Bardi, os documentos históricos só podem ser devidamente resgatados pelo presente, quando atualizados criticamente.

A sua crítica recai sobre uma vertente do Movimento Pós-Moderno que utiliza documentos de uma forma absolutamente acrítica e despropositada, em nome da consolidação do poder dominante, que é o do capital.

Também o termo monumento tem mais de um sentido. Ele pode indiciar a construção proposital de um passado, por aqueles que têm forças para fazê-lo. Nesse caso, sua função é formar uma memória oficial celebrativa, de caráter estático e estéril. No entender da arquiteta, é essa conceituação de monumento que vem 
sendo empregada insistentemente no Ocidente. Isso dificulta uma construção da história que seja mais abrangente e autêntica, mas não a inviabiliza:

A história é velha. Estão voltando os arcos e as colunas do nazi-fascismo, a história tomada como Monumento e não como Documento. A história é aquilo que transforma os Monumentos em Documentos. [...] Conclusão: estamos ainda sob o céu cinzento do pósguerra. [...] Mas o que existiu de verdade foi a Guerra, que ainda continua, como continuam as grandes resistências. (BARDI, apud FERRAZ, 1993, p. 226)

No entender de Lina Bo Bardi, o termo "monumental" pode ter outro significado, que diga respeito às "ações coletivas de grandes arranques sociais". Ela afirma a necessidade de que se distinga a noção "monumental" do termo "elefantíase". Afirma:

O monumental não depende das "dimensões". O Parthenon é monumental, embora a sua escala seja a mais reduzida. A construção nazi-fascista [...] é elefantíaca e não monumental; na sua impáfia (sic) inchada, na sua não lógica. O que eu quero chamar de monumental [...] é apenas um fato da coletividade, de consciência coletiva. (BARDI, 1967, p. 20).

Lina Bo Bardi reafirma a necessidade de que os monumentos sejam entendidos nesse sentido cívico coletivo. Assim compreendidos, eles têm a possibilidade de serem constantemente reapropriados por cada uma das gerações que passam a ter contato com eles.

Em diversos momentos do seu discurso a arquiteta trabalha com a questão dos documentos e monumentos, considerando-os de acordo com a sua própria interpretação.

Quando Lina Bo Bardi intervém em um espaço como o do Trianon, em São Paulo, ela o considera nessas duas dimensões. Trata-se de um espaço com valor histórico e desse modo deve ser tratado como um documento. Mas também é um monumento, um local representativo da coletividade, que deve ser mantido desse modo. É a partir destas considerações que Lina Bo Bardi formula as premissas para sua intervenção na Avenida Paulista: "Eu procurei no Masp, (...) recriar o ambiente do Trianon. Eu gostaria que lá fosse o povo. (...) Gostaria que crianças fossem brincar no sol da manhã e da tarde (sic)." (BARDI, 1967, p. 20). 
Ruínas, documentos e monumentos: são índices do passado que chegam ao presente em forma de fragmentos. Eles têm que ser resgatados. A reapropriação desses restos pressupõe uma atualização, que tem que estar atenta a todas as potencialidades do passado e do presente. Tem que ser ao mesmo tempo crítica e criativa.

\section{Restauração}

Durante o século XIX surgem as primeiras elaborações teóricas e recomendações práticas vinculadas com a conservação e restauração do patrimônio construído. Na Europa são formuladas duas teorias conflitantes, uma desenvolvida pelo francês Viollet-le-Duc (1814-1879) (9) e outra configurada pelo inglês John Ruskin (18191900) (10). No final do século XIX o método da "Restauração Científica" (11) é elaborado pelo italiano Camillo Boito (1836-1914) e sistematizado pelo seu conterrâneo Gustavo Giovannoni (1873-1947). É esse último quem tem um importante papel na constituição do primeiro documento internacional dedicado a estabelecer princípios gerais para restaurações: a "Carta de Atenas" de 1931 (12).

Novas discussões sobre esse mesmo tema são formuladas pelo austríaco Aloïs Riegl (1858-1905) (13). O autor é incumbido da tarefa de organizar um plano para a conservação dos monumentos públicos do seu país, e com isso acaba elaborando importantes reflexões sobre a problemática da preservação. No decorrer do século $X X$, surgem outros teóricos que se dedicam à mesma questão. É o caso do italiano Cesare Brandi (1906-1988) (14), que constrói uma teoria que parte de um embasamento fenomenológico. Todos esse desenrolar teórico acaba possibilitando que se configurem as bases de um segundo documento que promove recomendações internacionais sobre restaurações, que é a "Carta de Veneza", de 1964 (15). Tal movimentação intelectual em torno do tema da restauração é bastante prolífica. Na Itália os arquitetos Carlo Scarpa e Franco Albini passam a desenvolver importantes trabalhos, baseados no método denominado "Restauro Crítico" (16).

No caso do Brasil, as preocupações com a preservação patrimonial surgem no século XX. É o Estado quem passa a definir as políticas preservacionistas e os métodos com os quais devem ser restaurados os monumentos nacionais (17). 
Lina Bo Bardi tem um posicionamento singular diante de todas essas questões levantadas pela teoria e pela prática restaurativa internacional e nacional. Ela estabelece uma atitude independente, que somente encontra correspondência nos parâmetros de restauro difundidos pela "Carta de Veneza" e pelo "Restauro Crítico".

Os critérios de restauração formulados pela arquiteta estão baseados em suas concepções sobre o tempo histórico. É a partir da sua compreensão das relações entre passado, presente e futuro que Lina Bo Bardi elabora suas críticas a certos métodos de restauração, tais como aquele difundido por Viollet-le-Duc, e aquele aplicado em âmbito nacional pelo Sphan. A arquiteta condena esses tipos de intervenção que buscam uma fictícia restituição de uma condição prévia:

A palavra restauração lembra, em geral, as tristes restaurações. Dentro de um certo período histórico precedente, há a destruição de um edifício, isto é, a destruição pelo Tempo, ou pelos homens, por incidentes, por uma guerra, um terremoto. Em geral a restauração é a restituição de um estado primitivo de tempo, de lugar, de estilo. Depois da Carta de Veneza, de 1965 , as coisas melhoraram, mas aquela marca de ranço numa obra restaurada permanece. É muito difícil não perceber ou sentir isso num restauro. (BARDI, apud FERRAZ, 1993, p. 292)

No seu entender, essas posturas refletem uma compreensão do passado carregada de mofo, que não possibilitam mudanças, mas sim repetições. Mas Lina Bo Bardi não pretende manter o passado intacto. Para ela o passado só pode ser resgatado a partir das novas relações que ele estabelece com o presente. Essas conexões têm que ser capazes de extrair do emaranhado temporal todos aqueles elementos, sejam eles implícitos ou explícitos, que ainda sejam significativos para o presente. A atualidade tem que ser capaz de dialogar ativamente com o passado.

Esses entendimentos sobre o tempo histórico fornecem as bases para que Lina Bo Bardi estabeleça os critérios que devem guiar os seus restauros.

A eleição dos elementos que merecem ser preservados no patrimônio construído não aponta nenhuma de suas etapas como a mais paradigmática, não fixa nenhum estilo como o mais emblemático. Todos os momentos vividos pelo edifício têm que 
ser levados em consideração, bem como todos os estilos que vão se sobrepondo a ele. A trajetória de vida - e de transformações - do patrimônio edificado precisa ser mantida e evidenciada.

No caso de haver necessidade de substituição de certos elementos arquitetônicos, é importante que se evidencie esse procedimento. A troca deve estar em harmonia com o conjunto.

Quanto aos novos acréscimos, eles também devem ter o direito à expressão - eles têm que ser nitidamente contemporâneos. Essa atualidade pode ser demonstrada de diversas maneiras. Por vezes as novas incorporações são sutis, porém poderosas. Em outras ocasiões são bastante brutas, utilizando-se firmemente de técnicas e materiais modernos.

Assim sendo, para que uma restauração seja realmente válida ela precisa de um marco de contemporaneidade: ela tem que se posicionar firmemente no presente. Afinal, é a partir da atualidade que são lançados os olhares sobre o passado que possibilitam novas conjunções entre os tempos históricos. Essa atitude indica que os futuros presentes também podem estabelecer com seus passados as mesmas relações de inacabamento, e assim sucessivamente.

Mas os critérios bobardianos de seleção dos elementos a serem preservados, no patrimônio construído, vão além de aspectos formais e materiais.

Quando é necessária a restauração de centros históricos, deve-se valorizar o patrimônio humano envolvido. É importante ater-se aos homens que habitam e trabalham nesses locais. Deve-se levar em consideração que são eles que qualificam esses espaços e os preenchem de vida. Ao realizar uma restauração de um centro histórico, é fundamental que os habitantes e trabalhadores sejam mantidos no local e que se ofereçam a eles condições dignas de vida. Restaurar passa a ser um ato de responsabilidade social. 
Para Lina Bo Bardi, é justamente a presença humana que fornece o substrato a cada restauração. Cada edifício de um centro histórico é um reservatório de vida, testemunho do trabalho dos homens e da solidariedade transmitida entre eles.

É a falta de sensibilidade para a preservação desses aspectos humanos que faz com que a arquiteta condene uma série restauros europeus: "Não vai ser como na Itália e na França, deixando as casinhas bem bonitinhas, mandando quem mora lá embora e depois levando para o lugar as boutiques, as madames, as galerias de arte." (BARDI, apud CARVALHO; ALMEIDA, 1988, p. 40)

Mais uma vez o olhar bobardiano se dirige para o passado, buscando captá-lo na sua mais plena intensidade. É a pulsação vital do patrimônio que possibilita que se estabeleça uma conexão produtiva entre os tempos históricos. Todas essas considerações possibilitam que a arquiteta rompa com os métodos de restauração que considera ultrapassados:

O velho método romântico de recomposição inaugurado por Viollet-le-Duc foi superado e depois substituído pelo método da restauração científica, cujo principal representante foi o Prof. Gustavo Giovannoni. Na Itália, são ambos não somente superados, mas inúteis nesse momento de moderna restauração crítica. (BARDI, apud Jornal da Bahia, 1963, não pag.)

O método que Lina Bo Bardi afirma ser o mais coerente é o do restauro crítico, que leva em consideração a dinâmica de transformações de cada edifício, e se pauta na consideração da história viva de cada um deles. Esse método já é preconizado por ela quando intervém no Solar do Unhão, em Salvador (1963). Posteriormente os mesmos conteúdos básicos já afirmados pela arquiteta ganham uma difusão internacional, através da Carta de Veneza. Para Lina Bo Bardi, a restauração crítica parte de algumas premissas básicas que devem ser levadas em consideração: "Tem por base o respeito absoluto por tudo aquilo que o monumento representa como poética dentro da interpretação moderna de continuidade histórica, procurando não embalsamar o monumento mas integrá-lo ao máximo na vida moderna." (BARDI, apud Jornal da Bahia, 1963, não pag.) 
A difusão da restauração crítica não impossibilita que ainda haja adeptos da petrificação dos edifícios, dos homens e do tempo. No caso do Brasil, é bom lembrar que no mesmo ano da promulgação da Carta de Veneza, o país mergulha numa ditadura militar, que dificulta qualquer leitura crítica da história. E o Brasil luta até hoje para sair dessa asfixia histórica.

Como se pode notar, o tema da restauração está massivamente presente nos escritos de Lina Bo Bardi. O projeto restaurativo bobardiano se pauta em um inacabamento constitutivo, em possibilidades de mútuas transformações do passado, do presente e do futuro.

\section{Conclusões}

Ao seguir as pistas deixadas por Lina Bo Bardi - materializadas tanto nos seus textos como nas suas obras arquitetônicas - é possível vislumbrar o seu entendimento sobre o tempo e a história.

A obra bobardiana desenvolvida no Brasil mostra que a arquiteta mantém uma enorme coerência entre o que diz e o que faz. Lina Bo Bardi vai estabelecendo ao longo de sua vida uma peculiar compreensão sobre o tempo e a história. $O$ conjunto de princípios formulados por ela tem imediata repercussão na sua produção arquitetônica. Mais do que isso, teoria e prática se complementam, se tecem conjuntamente.

Os restauros conduzidos por Lina Bo Bardi evidenciam que são estruturados a partir de uma série de princípios relacionados com o seu entendimento sobre o tempo e a história. Mas é importante observar que tais princípios também orientam a conduta bobardiana em outras vertentes de sua produção arquitetônica.

Ao conceber a noção de presente histórico, Lina Bo Bardi explicita seu posicionamento diante da história. Essa parte, impreterivelmente, do presente da consciência humana em direção ao turbilhão, adentrando no passado, no presente e também no futuro, não os deixando intactos. 
Isso significa que a arquiteta transfere para cada ser humano a tarefa de construir a história, tendo como base os elementos materiais disponíveis. Em seus restauros e em suas outras obras, Lina Bo Bardi promove os canais de acesso para que as pessoas possam se reconhecer enquanto agentes históricos, capazes de modificar seus rumos pessoais e coletivos, referentes tanto ao passado, como ao presente e ao futuro.

Lina Bo Bardi não exonera as pessoas diante do compromisso de suas próprias vidas. Suas palavras e seus restauros são uma convocação para que os seres humanos abandonem a passividade, se responsabilizem diante de si mesmos e dos seus semelhantes, se prontifiquem a modificar a história.

Com tais posturas, Lina Bo Bardi acaba executando restauros de grande vigor, capazes de estabelecer um contraponto a muitas práticas restaurativas nacionais, pautadas em uma compreensão da história carregada de imobilismo e passividade. Sua atitude, pelo contrário, afirma a necessidade do rompimento com esse panorama.

Para ela, o restaurador tem que ser capaz de respeitar as preexistências, tem que ser hábil ao inserir novas intervenções. Tem que se mover ao mesmo tempo com precaução e desprendimento, transformando o passado, o presente e o futuro. Mas o restaurador tem que estar atento, sobretudo, às existências humanas. São elas que devem mover esses empreendimentos restaurativos.

As restaurações realizadas por Lina Bo Bardi demonstram a existência de uma forte conexão entre seus postulados teóricos e a sua atuação prática. É emblemática a sua intervenção no Sesc-Pompéia em São Paulo (1976-1982). Nessa oportunidade a arquiteta demonstra que os seus conceitos de tempo, história e restauro podem ser observados não somente nos seus textos, mas também na sua obra construída.

No caso da restauração desta antiga fábrica de tambores, esses conceitos se manifestam tanto na preservação das suas características físicas, como também das vivenciais. 
São preservados aspectos formais e espaciais fundamentais do local. Lina Bo Bardi mantém inúmeras características do projeto inicial realizado em 1938, aceita muitas das suas modificações posteriores e acrescenta várias novas intervenções. Todas as alterações são visivelmente contemporâneas.

Ao atuar desse modo, Lina Bo Bardi não busca fixar algum ponto originário ou conclusivo que sirva de referência para todas as intervenções executadas no complexo industrial. Não se estabelece um retorno a um estado primitivo que remeta à etapa de formação da fábrica, e igualmente não se coloca a intervenção contemporânea como o ápice da trajetória do conjunto fabril.

A restauração não estabelece uma interpretação da história de caráter único e definitivo. Não se promove uma versão do passado, do presente ou do futuro que encerre uma imagem fixa, que deva ser permanentemente reeditada nas consciências de cada geração. Pelo contrário, estimula-se uma leitura da história pautada em uma imagem dinâmica, que seja reativada permanentemente em cada consciência.

Mas a atuação de Lina Bo Bardi não se limita à manutenção de determinadas características físicas do local. Sua restauração também possibilita a preservação de uma condição de existência digna. A arquiteta promove a conservação do caráter pulsante, público e democrático que o local possuía antes da sua intervenção, quando já era intensamente ocupado por crianças, adultos e idosos usuários dos galpões industriais. Lina Bo Bardi reconhece que toda essa vivacidade está concentrada em um ambiente fabril, de onde procede toda uma carga histórica: o início da industrialização paulistana, o cotidiano de trabalhadores comumente submetidos a explorações. A restauração desencadeada por Lina Bo Bardi assegura o resgate desse passado oprimido.

Ao examinar as restaurações realizadas pela arquiteta, percebe-se que os conceitos de tempo e de história não são neutros, mas implicam em tomadas de posições diante do mundo. As manifestações desses conceitos nas atuações de Lina Bo Bardi fornecem elementos para que se repense o restauro e o papel do restaurador na 
sociedade. Lina Bo Bardi sublinha que ambos não podem se isentar do dever da construção de uma sociedade mais justa e mais humana.

\section{Notas}

(1) Lina Bo Bardi nasce em Roma, em 1914. Reside na cidade até 1940, quando se forma na Faculdade de Arquitetura da Universidade de Roma. Transfere-se para Milão. Chega ao Brasil em 1946 e se naturaliza brasileira em 1951. Morre em São Paulo, em 1992.

(2) Lina Bo Bardi é influenciada pelos preceitos difundidos pelos arquitetos (emblematizados nas figuras de Le Corbusier, Mies van der Rohe e Walter Gropius) e historiadores (especialmente Pevsner e Gideon) vinculados com o Movimento Moderno.

(3) Zeitgeist (Espírito da época) é um conceito hegeliano que aponta que a cada determinado tempo e lugar correspondem certas características específicas. Tal termo é apropriado e difundido pela historiografia oficial do Movimento Moderno, através de Pevsner e Gideon. Afirma-se que a estética modernista é aquela que expressa com mais validade o espírito da era da máquina. Vide Araújo, Anete. "A construção do Movimento Moderno: entre a arquitetura e a historiografia." Em: (Oliveira; Cardoso, org., 1997, p. 71-72) e (Arantes,1998, p. 48).

(4) É importante observar que Lina Bo Bardi enfrenta, durante a Segunda Guerra Mundial, o fascismo na Itália. Após o fim da Guerra a arquiteta considera que os "velhos fantasmas" fascistas estão retornando, fato que a impele a sair da Itália.

(5) Lina Bo Bardi filia-se em Milão, junto a Rogers, Pagani e outros ao MSA (Movimento Studi per l'Architettura). O MSA introduz uma revisão dos princípios do Movimento Moderno.

(6) A questão do tempo e da história na obra de Lina Bo Bardi também foi estudada por outros pesquisadores, entre os quais ressaltam-se alguns, referidos na bibliografia: (Campello, 1997), (Lépori, 1997), (Oliveira, 1994), (Oliveira, 1995).

(7) O Sphan - Serviço do Patrimônio Histórico e Artístico Nacional é oficialmente criado em 1937. Nos seus quadros encontram-se nomes ligados ao modernismo brasileiro, como Mário de Andrade e Lúcio Costa. A prática preservacionista direciona sua ação para a conservação de bens arquitetônicos e artísticos relacionados com os períodos colonial e barroco. Sua atenção também se volta prioritariamente para a arquitetura religiosa. Vide (Fonseca, 1997, p.117-119 e p.162).

(8) Os anjos freqüentam o pensamento de Walter Benjamin. Gagnebin comenta: "Se os anjos povoam [...] o pensamento de Benjamin, esse povoamento subverte, [...] a idéia mesma de uma posição estável, de uma pátria definitiva conquistada, de um enraizamento substancial, seja ele de ordem teórica ou existencial". Vide (Gagnebin, 1997, p.123).

(9) O método configurado por Viollet-le-Duc afirma que a restauração de um edifício deva se pautar na "restituição de um estado de inteireza que pode jamais ter existido em um determinado momento". Trata-se da 
restituição de um estado ideal, que é considerado acessível graças à possibilidade do conhecimento dos princípios arquitetônicos geradores dos edifícios. Tais princípios são de ordem estrutural. Dessa forma, é fixado um método restaurativo que está vinculado a uma investigação histórica, que tem por função estabelecer tais princípios fundamentais e imutáveis que devem guiar não só os restauros, mas também as novas arquiteturas.

(10) John Ruskin parte da consideração de que a arquitetura deve ser conservada não só para garantir a preservação das produções materiais, mas também dos modos de vida e das virtudes morais. Para ele, tudo o que é fruto do esforço humano deve ser preservado. No seu entender, as heranças do passado têm o valor de relíquias, e devem ser mantidas intactas. Assim, para Ruskin, a conservação dos edifícios antigos não significa a sua restauração, mas sim a sua manutenção. Restaurar, para ele, significa destruir, e se configura em "uma mentira do princípio ao fim." Isso o posiciona em desacordo com a teoria de Viollet-le-Duc.

(11) Há alguns pontos principais lançados pelo método da "Restauração Científica": os trabalhos de conservação devem ser priorizados; quando for de fato imprescindível que haja alguma intervenção, ela tem que ser a menor possível, mas nitidamente moderna; caso sejam adotados novos acréscimos, eles devem seguir linhas simplificadas, buscando a mínima notoriedade; devem ser respeitados todos os elementos somados ao edifício que tenham valor artístico, não somente aqueles construídos na sua fase inicial. Vide: (Lacerda, A; Lins, E; Cardoso, L, s/d: s/p)

(12) Trata-se da Carta de Atenas dos restauradores, aprovada pelo Quarto Congresso Internacional de Arquitetura Moderna - CIAM - realizado em Atenas, Grécia.

(13) As reflexões formuladas por Aloïs Riegl partem da tentativa de definição do "caráter do culto moderno aos monumentos". Sua análise está baseada na crítica à noção tradicional de monumento e na assimilação dos novos valores que lhe são atribuídos. Tais valores trazem novas implicações para a questão da preservação e restauro.

(14) Brandi estabelece uma teoria segundo a qual "a restauração constitui o momento metodológico de reconhecimento da obra de arte em sua consistência física e na sua dupla polaridade estética e histórica, em ordem a sua transmissão ao futuro". Para ele, a restauração é uma operação legítima que não deve conceber o tempo como algo reversível, nem a abolição da história. A ação restauradora não deve ser secreta ou quase fora do tempo, mas deve oferecer os meios para ser delimitada como evento histórico que é. (BRANDI, 1988)

(15) A Carta de Veneza é um documento internacional sobre conservação e restauração de monumentos e sítios, promulgada em Veneza, em maio de 1964. Ela procede a Carta de Atenas de 1931, o primeiro documento a estabelecer princípios internacionais para conservação e restauração. Entre os pontos difundidos pela Carta de Veneza, é importante que sejam sublinhados alguns, os quais Lina Bo Bardi incorpora: ARTIGO 9 - "A restauração é uma operação que deve ter caráter excepcional. [...] Todo trabalho complementar reconhecido como indispensável por razões estéticas ou técnicas destacar-se-á da composição arquitetônica e deverá ostentar a marca do nosso tempo". [...] ARTIGO 11 - "As contribuições válidas de todas as épocas para a edificação do monumento devem ser respeitadas". [...] ARTIGO 12 - "Os elementos destinados a substituir as partes faltantes devem integrar-se harmonicamente ao conjunto, distinguindo-se, todavia, as partes originais a fim de que a restauração não falsifique o documento de arte e de história". ARTIGO 13 - "Os acréscimos só poderão ser tolerados na medida em que respeitarem todas as partes interessantes do edifício, seu esquema tradicional, o equilíbrio de sua composição." Vide (http:// www.iphan.gov.br/iphan/veneza.htm) 
(16) Para Cecília Rodrigues dos Santos, o restauro crítico é "releitura do objeto e do lugar e uma interferência ativa e transparente na recomposição final". Para ela, Carlo Scarpa "revela-se o arquiteto descobridor dos segredos construtivos desses edifícios; cultivando um profundo respeito pela tradição ao mesmo tempo que só reconhece valor na realidade quando transfigurada; buscando, através do seu trabalho, uma revalorização da obra mais eloqüente do que funcional". (Santos,1992, p.55)

(17) Paul Meurs comenta os critérios de restauração postulados por Lúcio Costa: "É interessante notar que ele insistiu desde o início na conservação das casas em sua forma mais primitiva e não considerava os estilos importados do século passado importantes. Em trabalhos de restauração, as modificações posteriores feitas em janelas, coberturas e ornamentos eram sempre desfeitas para que se restabelecesse o estado original." (Meurs, 1995, p.79) Críticas a essas opções só passam a ganhar vulto nos anos 70. Vide (Fonseca, 1997, p.117 -119 e p.162).

\section{Referências Bibliográficas}

BARDI, Lina Bo. Duas construções de Oscar Niemeyer. Habitat, n. 2, p. 6-9, jan./mar. 1951.

Casa na Bahia. Habitat, n. 8, p. 16-17, jul./set. 1952.

A Catedral. Habitat, n. 14, não pag., fev. 1954.

Contribuição propedêutica ao ensino da teoria da arquitetura. 1957. 94 f. Tese apresentada ao concurso da cadeira de Teoria da Arquitetura-Faculdade de Arquitetura e Urbanismo, Universidade de São Paulo, São Paulo, 1957.

Coluna Ôlho sobre a Bahia-7. Diário de Notícias, 19 out. 1958. Não paginado.

O novo Trianôn 1957-1967. Mirante das artes, n. 5, p. 20-23, set./out. 1967.

Armadilhas e pedras no caminho do novo Governo. Problemas brasileiros, n. 240/243, p. 20-32, dez./jan. 1985.

Uma aula de arquitetura. Projeto, n. 149, p. 60-62, jan./fev. 1992.

Tempos de Grossura: o design no impasse. São Paulo: Instituto Lina Bo e Pietro Maria Bardi. 1994. 79 p.

BIERRENBACH, Ana Carolina de S. Os restauros de Lina Bo Bardi e as interpretações da história. Salvador: MAU/UFBA, 2001. 185 p.

BRANDI, Cesari. Teoria de la restauración. Madrid: Alianza Editorial. 1988. 149 p. 
CARVALHO, Bernardo; ALMEIDA, Gilberto. O casal ousadia - o nome italiano Bardi tornou-se sinônimo perfeito de arquitetura e das artes brasileiras. Afinal, n. 38-41, 17 maio 1988.

FERRAZ, Marcelo C. (Org). Lina Bo Bardi. São Paulo: Instituto Lina Bo Bardi e Pietro M. Bardi, 1993. 333 p.

FONSECA, Maria Cecília L. O patrimônio em processo: trajetória da política federal de preservação no Brasil. Rio de Janeiro: Editora UFRJ/IPHAN, 1997. 316 p.

GAGNEBIN, Jeanne Marie. Sete aulas sobre linguagem, memória e história. Rio de Janeiro: Editora Imago, 1997. $186 \mathrm{p}$.

LACERDA, A; LINS, E; CARDOSO, L. Antecedentes do restauro moderno. Texto datilografado, s.d. Não paginado.

LEFÉVRE, Carolina. Entrevista - Lina Bo Bardi. Caramelo (FAU-USP), n. 3, não pag., out. 1991.

MEURS, Paul. A identidade brasileira e o moderno - a obra de Lina Bo Bardi. De Architect, n. 62-77, maio 1994.

MUSEU salva a cultura da Bahia e o passado pela fé. Jornal da Bahia, Salvador, 1963. Não paginado.

OLIVEIRA, Olívia F; CARDOSO, Luis Fernandes. (Org.). (Re)discutindo o Modernismo - Universalidade e Diversidade do Movimento Moderno em Arquitetura e Urbanismo no Brasil. Salvador: MAU, 1997. 301 p.

RIEGL, Aloïs. El culto moderno a los monumentos. Madrid: Visor, 1987. 99 p.

RUSKIN, John. A lâmpada da memória. Apresentação, tradução e comentários críticos por Odete Dourado. Salvador: MAU-UFBA, 49p. (PRETEXTOS, série B, Memórias 2).

SANTOS, Cecília Rodrigues. Assim, nas bordas e por dentro, os ratos foram roendo a nossa cidade da Bahia. Projeto, p. 54-55, n. 149, jan./fev. 1992.

VIOLLET-LE-DUC, E. E. Restauro. Apresentação, tradução e comentários críticos por Odete Dourado. Salvador: MAU-UFBA. 52 p. (PRETEXTOS, Série B, Memórias 1).

\section{Bibliografia complementar}

(Neste artigo são citados somente alguns textos relevantes utilizados na elaboração da dissertação de mestrado, excluindo-se qualquer bibliografia posterior à sua realização).

BENJAMIN, Walter. Magia e técnica, arte e política. São Paulo: Brasiliense, 1993. 235 p.

CABRAL, Maria Cristina N. O Racionalismo arquitetônico de Lina Bo Bardi. 1996. 95 f. Dissertação (Mestrado)Pontifícia Universidade Católica do Rio de Janeiro, Rio de Janeiro, 1996.

CAMPELLO, Maria de Fátima. (1997). Lina Bo Bardi: as moradas da alma. São Carlos, FAU-EESC/USP, Dissertação de Mestrado, 1997, 176p. 
FERRAZ, Marcelo. Salsinha de poucos pratos. A tarde cultural, 23 de outubro de 1993 (1993b), Suplemento Cultural, pp.3.

FERRAZ, Marcelo C. A poesia vital de Lina Bo Bardi. Folha de São Paulo. 8 de dezembro de 1996. Suplemento Mais! Caderno 5, pp. 14.

GAGNEBIN, Jeanne Marie. História e narração em Walter Benjamin. São Paulo: Perspectiva, 1994. 131 p.

GUIMARAENS, Maria da Conceição. Dois olhares sobre o patrimônio cultural: Lina e Lygia. Rio de Janeiro: Escola de Comunicação da UFRJ, 1993. 106p.

LÉPORI, Ana Paula de O. Lina Bo Bardi - um olhar sobre as possibilidades populares do Brasil. Barcelona: ETSAB-UPC, Dissertação de Mestrado, 1997.

OLIVEIRA, Olivia F. Hacia Lina Bo Bardi. 1994. 86 f. Dissertação (Mestrado)-ETSAB/UPC, Barcelona, 1994.

OLIVEIRA, Olívia F. Quarto de arquiteto. Óculum, n. 5/6, p. 82-87, 1995.

* Arquiteta e historiadora. Mestre pela FAU-UFBA (2001) e doutora pela ETSAB-UPC (2006).

Este trabalho é baseado na dissertação de mestrado "Os restauros de Lina Bo Bardi e as interpretações da história", realizado no MAU-UFBA (2001), sob a orientação do Prof. Dr. Pasqualino Maganvita, e contou com recursos da CAPES. 